\title{
Teaching Reform of Engineering Geology for Foreign Students
}

\author{
YANG Dayong, XIE Zhiwei, You Yingchun \\ The Traffic Engineering College of Shenyang Jianzhu University \\ Liaoning, Shenyang 110168
}

\begin{abstract}
To further improve the teaching effect of engineering geology course for overseas students of Shenyang Jianzhu University, the teachers carried out various and pertinent reforms. The reform measures include the selection of practical teaching concepts, selection of foundation and suitable teaching content, using multimedia teaching and a lot of photos, animated gifs and videos, improving the examination system focusing on comprehensive ability. The curriculum after the reform pays more attention to the combination of teaching and practice, training the students' comprehensive ability, and emphasizing the initiative of the students. Reform has been recognized by students. Class enthusiasm and academic performance has improved significantly. In the reform, we adopted the teaching method of giving priority to pictures and giving priority to students' learning, and achieved good results.
\end{abstract}

Keywords-civil engineering; foreign students; engineering geology; teaching reform

\section{INTRODUCTION}

In recent years, Chinese enterprises have gone abroad and began to take charge of or participate in various international projects [1]. High quality engineering and construction management has been recognized by many countries in the world, and it has also established a good reputation for the personnel training system of engineering construction. Therefore, some countries hope that the colleges and universities in China can help them train relevant professionals in engineering construction. In order to carry out more extensive international exchanges and scientific and technological cooperation, Shenyang Jianzhu University opened an international college in 2004 to recruit international undergraduates from major countries in Africa and the Middle East.

The engineering geology course is a professional basic course of Shenyang Jianzhu University International Institute for civil engineering students. This course is based on the theory of geology, through investigation, mapping and other technical means, to solve the geological problems related to various engineering activities [1,2]. The main task of the course is to train the students to be able to read the geological data and analyze the geological conditions of the project independently, so as to achieve the goal of solving the geological problems related to various projects [1-3]. Therefore, it is necessary for civil engineering majors to set up this course.

Fund Project: Subject education program of Shenyang Jianzhu University (No. XKHY2-94); Education, teaching and research project of China Construction Education Association in 2017 (No. 2017077)

Brief introduction of the author: Yang Dayong (1982- ), Male, Zunhua, Hebei, Doctor, Lecturer, e-mail: ydy1120@163.com.

\section{THE CURRENT DIFFICULTIES FACED IN TEACHING}

(1) Students have poor knowledge base. These international class students mainly from Africa and Middle East countries are poor in knowledge bases compared with the domestic students. Moreover, the education and teaching level in different countries are also uneven, and the knowledge base of students in the same class is very different. The engineering geology course involves wide knowledge of the general geology, geotechnical engineering, hydrology geology, soil mechanics and rock mechanics [2]. The students should master mathematics, mechanics, chemistry and other aspects of knowledge for the higher level. The contradiction between the teaching requirements and the knowledge base of the students has brought great difficulties to the teaching work.

(2) The English level of students is uneven. The languages of students in the international class are Arabic, English and French. Some French or other non-English speaking students have poor English proficiency and have difficulty in reading English textbooks independently. They don't even understand what the teacher says in the class.

(3) Lacking of suitable English textbooks of engineering geology. At present, the teaching material used in the course is "Engineering Geology" written by F. G. Bell, and also referred to "Foundations of Engineering Geology" written by Tony Waltham. The two textbooks can comprehensively expound basic theory knowledge of engineering geology [4]. But the knowledge in the book is too difficult to understand for nongeological professional students in the international class. There are not enough suitable English textbooks of engineering geology in china. In addition, the description of textbooks is still too much for students to understand and memorize large, boring concepts and description. Therefore, only part of the basic and important chapters and contents can be singled out for teaching.

(4) Teachers have limited English proficiency. International class students are very poor in Chinese, and basically only a few simple daily greetings vocabulary. Therefore, in the course of teaching, the teacher must be taught in English. This puts a high demand on the teacher's English level. At the same time, because of the international students' English accent problem, the communication between teachers and some students is not very smooth. For a large number of professional vocabulary and fluent oral expression, requirements of the teacher's English proficiency and curriculum preparation are very high. 
It has made a great deal of pressure on the teachers because of the crowding out of the teaching preparation time.

\section{CURRICULUM REFORM MEASURES}

In view of these special problems in teaching practice, it is urgent to reform the engineering geology course for international students. For the reform of engineering geology course, a series of deep researches have been carried out by the predecessors. In recent years, bilingual teaching in engineering geology has started in some domestic universities, such as Changsha University of Science and Technology, Chongqing Jiaotong University and Dalian University of Technology [1, 4, 5]. However, international students have many special situations compared with those of ordinary students in china. To teach foreign students, the teaching methods can not directly copy the experience of bilingual teaching in other colleges and universities. It is necessary to carry out purposeful reform in light of specific conditions. As a professional teacher of engineering geology, according to the experience, based on the focus on the laws of human development and the function of the curriculum, I carried out a series of meaningful reforms in teaching content, teaching methods, assessment methods [5$8]$.

\section{A. Setting up correct teaching idea.}

According to the general requirements of modern society for talents, the engineering geological teaching ideas was determined to be "strengthening the foundation, widening the knowledge, based on the frontier; using modern teaching methods, paying attention to practical training and innovation ability; emphasizing the course trait, training the comprehensive quality" [6]. For the special case of international students, the standard of the teaching content should not be ambitious, not divorce from the actual knowledge base and the understanding and absorptive ability of the students. Therefore, the teaching objective is transformed from the traditional form of knowledge transmission to the form of ability training, so that students can really understand, learn and practice".

\section{B. Selecting suitable teaching content.}

When choosing the specific teaching materials and teaching contents of engineering geology course, we should pay attention to both aspects of basic and professional requirements [9]. First of all, as a basic course for sophomores majoring in civil engineering, students lack the relevant header courses as basic knowledge reserves. So the teaching contents should focus on the basic knowledge, theory and method, which enable students to establish a comprehensive and systematic knowledge system about engineering geology in the mind [9]. Secondly, the content of the teaching material should be enough to focus on the specialty, and must be able to highlight the practical application of engineering geology in civil engineering [9]. For example, soil with different grain sizes and cohesive properties, the basic theory and formula for calculating the pressure of retaining walls are completely different, which require students to compare, understand and memorize for different engineering realities.
The choice of teaching materials should be based on a classic English textbook, and refer to other English materials. The specific teaching contents corresponding to the teaching progress should be selected from them. This is to ensure that the basic concept, principle and method of the excellent teaching materials is reserved and the profound and difficult part is abandoned. Then the written text should be transformed into classroom teaching language in simple words and statements. When selecting English textbooks, we also need to refer to some domestic Chinese textbooks. After all, the compiling ideas, the knowledge system, the teaching emphases and the cases listed in the domestic teaching materials have more advantages and Chinese characteristics.

\section{Selecting the appropriate teaching methods.}

Because the teaching methods of only text and language interpretation are too boring, in particular, it involves specific geological concepts, such as the appearance of structural planes, stereographic projection, mineral luster and so on. It is difficult for students to understand. Some students will drop their interests in lectures because they don't understand it well. In order to improve the quality and efficiency of teaching, it is very important to prepare suitable multimedia courseware for students. The multimedia courseware needs to be in the form of pictures, diagrams, charts and so on. It should be interpreted as few words as possible. It is easy to teach the students geological concept, dull field geological phenomena and engineering geological problems in a more intuitive and more simple form, so that students can immediately have a direct and profound impression, for quick understanding and memory.

Much of the knowledge of geology is derived from geological practices, and then summed up into knowledge. Therefore, students are allowed to directly understand specific geological practices in the form of pictures and diagrams so that students can reduce misunderstandings caused by speculation. For example, color, streak, luster, cleavage, fracture and other physical properties, for students of never seen mineral samples, it is hard to understand the specific meaning of the concept. The multimedia courseware, equipped with a large number of detailed pictures, will enable students to produce a direct sense of the impression, greatly improving their learning efficiency.

At the same time, the applications of flashes, dynamic pictures, and videos can effectively show the geological engineering concept and terminology of volcano, plate tectonics, sedimentary rock formation and soil consolidation test. It can accurately and vividly demonstrate the common phenomena and problems in geology and engineering practice $[5,10]$. Through the step-by-step explanation and the principle demonstration of dynamic images, students can directly and vividly understand the geological entity structure, physical and mechanical properties with the change of time and space and the series of changes in the process. It helps students grasp the change regularity and the essence, mechanism, improve their understanding of the principle of engineering geology, and effectively reduce the understanding deviation and time waste caused by the boring text understanding $[5,10]$. 


\section{Stimulating the enthusiasm of students in the classroom.}

It becomes the key point and difficulty of teaching engineering geology that how to stimulate and maintain the students' interest in learning so that they can master the main teaching contents. In the classroom, some students showed a lack of interest in, or being difficult to understand the contents. In addition to multimedia teaching, students can also be encouraged to think more and ask more questions to promote their enthusiasm. At the same time, organizing the group for class discussion, implementing individual special lectures and encouraging debate among students can help students more indepth understand of the basic teaching content. The using of a variety of teaching forms promoted their enthusiasm in class.

In the specific teaching content, attention should be paid to the teaching sequence arrangement and the teaching guide from the simple basic theory to the complex engineering practice step by step. For example, according to the physical and chemical characteristics of sedimentary rocks, students should be guided to consider the causes, material composition, particle structure and characteristics of certain sedimentary rocks as an entry point. Combined with specific engineering geological conditions, various engineering geological problems may be predicted, and corresponding engineering prevention measures and construction measures shall be put forward. Rules and logic is very clear with such teaching ideas, not only enable students to grasp the teaching content, but also can make students master effective learning methods [2].

In order to strengthen the combination of theory teaching and engineering practice and to improve the students' professional interest, we can join the hot engineering geological problems in the last few years. Students are encouraged to combine their knowledge with divergent thinking and try to analyze examples from different perspectives. For example, combined with the sudden large scale debris flow disaster happened in Zhouqu of Gansu province in August 2010, the geological environment and climate characteristics of the disaster will be analyzed, and the important role of geological condition changes in slope stability will be studied. Based on the large-scale landslide disaster happened in Shangpa Town of Yunnan province in June 2014, students can analysis the interaction of bedrock structure, topography, geological structure and groundwater, analysis the relationship between saturated soil and shear strength. This teaching method of combining specific engineering examples, can expand the students' knowledge, cultivate students' quality of integrating theory with practice, while effectively moving the enthusiasm of the students.

\section{E. Strengthening teaching practice.}

The special curriculum orientation of engineering geology determines that it must be a subject with strong practice and close connection with the actual work. Teaching in classroom is only one of the teaching methods. Its purpose is to ensure that students have the basic theoretical understanding of geological basis, various survey and test techniques and specific engineering geological problems. In order to further deepen the students to the basic concept, characteristics of various geological and engineering problems, to effectively link classroom learning and work practice, the corresponding practice teaching need to supplement.

The practice teaching of engineering geology course consists of two parts: laboratory experiment and field practice. The basic task is to let students to experience the field geological phenomena or engineering geological problems, to comprehensively study, in-depth analysis, feedback and deepen the students to the classroom teaching content and understanding. Practice teaching is the effective foundation. It can help students apply the theory of knowledge system to specific engineering work, which is an essential part of in the teaching of engineering geology [2].

\section{F. Improving students' abilities in all fields.}

In addition to teaching professional knowledge, we should also pay attention to cultivating students' abilities in many aspects. For example, some of the challenging problems, such as sedimentary rocks, metamorphic rocks, igneous rocks, which is more suitable for building materials? Teacher only asks questions in the relevant chapters and does not give specific answers. Students are required to make use of their time to develop their solutions and to search in the library or on the network independently. The strength, hardness, joint characteristics, engineering practice and other aspects of rock can be compared, and then a panel discussion. Finally, the results of the group discussion are explained by the group representatives in turn in class. The teacher will give only instructional advice throughout the process, but it is not the final judgment. Students who are in doubt can continue to explore and demonstrate. So, the whole problem solving process, the students will actively participate in, seriously think, stimulate their enthusiasm for learning, and promote the whole class to learn more content. At the same time, this way of learning can improve students' ability to explore problems, solve problems, communicate, discuss, think, question, explain, express and so on. It is very helpful to improve their comprehensive quality.

\section{G. Improving the assessment system.}

As an examination course, the ratio of the final examination with the usual score is $60 \%$ and $40 \%$. We should pay attention to the educational concept of "strong ability, innovation, wide range of knowledge, individuality" from two aspects of the content and form, while ensuring that can objectively reflect the students' level and learning attitude [2]. The form of the final examination paper includes many kinds of questions such as explanation of noun, filling in the blanks, brief questions and comprehensive analysis questions. They not only assess the basic knowledge, but also focus on the comprehensive analysis ability. Comprehensive analysis of questions, as much as possible by using the chart and drawing questions, is used to examine the students' mastery of the basic theory and to test their practical ability [9]. The usual results including questions answered in class, group discussions, job completion, classroom participation, need to be carefully recorded, fairly and reasonably. 


\section{CONCLUSION}

The reform of engineering geology curriculum has been unanimously approved by the students. The enthusiasm and academic performance of the students have improved significantly. The reform has abandoned the traditional teaching method of "text oriented, teacher oriented", adopted the teaching method of giving priority to pictures and giving priority to students' learning, and achieved good results.

To sum up, the English teaching mode of international class will become a new trend in the development of higher education in China, which meets the current needs of the internationalization of talents. The engineering geology course, like other professional courses taught in English, has only just begun. In the process of teaching in the future, need to gradually explore various problems found in the process of teaching, and take effective measures to reform, continue to explore, accumulate teaching experience. This requires teachers to improve their ability in all aspects and establish a harmonious relationship between teachers and students, and make every effort to improve the English Teaching of engineering courses in international class.

\section{REFERENCES}

[1] Nian Tingkai. English teaching reform on engineering geology course in the international class of civil engineering specialty[J]. Journal of architectural education in institutions of higher learning, 2014, 23(1): 99-101.

[2] Bai Mingzhou, Wang Meng, Liu Ying, Gong Hui. Teaching reformation of Engineering Geology [J]. Journal of Architectural Education in Insitutions of Higher Learning, 2006, 15(2): 93-96.

[3] Han Meilian. The Application of Engineering Geology Course in the Modern Engineering Practice [J]. Science \& Technology Vision, 23-24.

[4] Jiang Haifei, Xie Yuanguang, Tang Delan. Bilingual teaching of engineering geology course in international civil engineering class[J]. Education teaching forum, 2015, 26: 123-124.

[5] Zhang Yongjie, Wang Guiyao, Zhou Dequan, Chen Yonggui. Bilingual teaching practice of engineering geology course[J]. Journal of architectural education in institutions of higher learning, 2014, 23(1): 94-98.

[6] Huang Fei, Yao Yuzeng, Liang Junhong, Li Guichen, Zhao Guojun. "Geomorphology and Quaternary Geology" Curriculum teaching research and reform practice[J]. Chinese Geological Education, 2004, 4(8): 67-70.

[7] Chen Jian, Shen Naiqi. Study on the training mode of the Interdisciplinary talents of Geological Engineering major[J]. Chinese Geological Education, 2011, 1: 18-21.

[8] Li Hujie, Cui Chunlong, Chen Tingfang. Research and practice on students' Engineering Attainment and Innovation ability training of Geological Engineering [J]. Chinese Geological Education, 2010, 3: 1417.

[9] Hu Kun, Xia Xiong. Discussion on teaching reform of engineering geology course for civil engineering specialty $[\mathrm{J}]$. Journal of Hubei University of science and technology, 2014, 34(8): 14-15.

[10] Zhang Yongjie, Wang Guiyao, Liu Longwu, Chen Jiejin. Practical teaching of engineering geology course for non-geological engineering students $[\mathrm{J}]$. Journal of architectural education in institutions of higher learning, 2013, 22(5): 141-144. 